Research Article

\title{
Field Test and Numerical Studies on Influences of PVD Spacing on Vacuum Treatment Effects of Dredged Slurry
}

\author{
Yanming Yu $\left(\mathbb{D},{ }^{1}\right.$ Junhui Sheng $\mathbb{D D}^{2}$ Li Shi $\mathbb{D}^{2},{ }^{2}$ and Zhijun $\mathrm{Hu} \mathbb{i D}^{1}$ \\ ${ }^{1}$ PowerChina Huadong Engineering Corporation Limited, Hangzhou 311122, China \\ ${ }^{2}$ College of Civil Engineering, Zhejiang University of Technology, Hangzhou 310014, China
}

Correspondence should be addressed to Li Shi; lishi@zjut.edu.cn

Received 24 March 2021; Revised 26 April 2021; Accepted 3 June 2021; Published 22 June 2021

Academic Editor: Chunshun Zhang

Copyright (c) 2021 Yanming Yu et al. This is an open access article distributed under the Creative Commons Attribution License, which permits unrestricted use, distribution, and reproduction in any medium, provided the original work is properly cited.

A field test was conducted on vacuum treatment effects of a dredged slurry ground considering three PVD spacing, i.e., 700, 800, and $900 \mathrm{~mm}$. The settlement and the pore water pressure dissipation were measured during the treatment period. As expected, the consolidation rate associated with closer PVD spacing case is higher than that of the larger spacing case. However, it is observed that the final and stable values of the settlement and the pore pressure dissipation of the close spacing case (e.g., $700 \mathrm{~mm}$ ) are about $17 \%$ higher than the case of larger PVD spacing (e.g., $900 \mathrm{~mm}$ ). The differences imply that enlarging the PVD spacing not only impedes the consolidation rate but also decreases the vacuum pressure in slurry. Numerical models incorporating the vacuum pressure attenuation effect and the clogging effect were established to reproduce the vacuum treatment process under the three PVD spacing. Good comparisons between the numerical and test results can be obtained given a proper account of vacuum attenuation and the clogging effect along the PVD depth. The comparison clarifies that, for vacuum treatment of slurry ground, the PVD spacing should be determined by due considerations both on the desired consolidation rate and on the pore water pressure that needs to be dissipated.

\section{Introduction}

With the rapid development of coastal cities, the demand for land continues to increase. Reclamation of land by dredging slurry is an effective way to solve the shortage of land resources. The "man-made" ground has to be improved before to serve as a construction site because the slurry is a mixture of fine particles (e.g. clay and silt) and large volume of water, and thus, of extremely low strength. Vacuum preloading is a common measure taken by industry to improve the soft ground via installing prefabricated vertical drains (PVDs) into the soil and connecting PVDs to the vacuum pumps. However, poor improvements have been frequently reported for vacuum treatment of dredged slurry. It is reported that the settlement, the dissipation of pore water pressure (PWP), and water yield are retarded substantially even at the early or middle stage of the designed treatment period [1-3]. The phenomenon is generally attributed to the clogging zone around the PVD [4-6]. The forming process of the clogging zone is generally initialized by soil particles moving towards the PVD membrane driven by seepage force and followed by particles accumulating on the membrane surface along with some particles entering into it [6,7]. The accumulated particles form a dense zone (i.e. the clogging zone) around the PVD. The zone is of very low permeability (less than $1 \%$ of permeability of the original slurry [8]) because the particles are packed by the vacuum gradient, which is in contrast to natural soil formed by gravity sedimentation. It is estimated that the vacuum gradient is about 10 times higher than the gravity force [7]. To solve the clogging problem, several engineering measures, including lime treatment [2], air pressurization [9], staged vacuum loading [10], and optimizations on membrane aperture and spacing of PVD, have been proposed and evaluated in the literature.

As for the influence of PVD spacing on effects of the vacuum preloading, Holtz [11] correlated improvement effect of soft soil foundation with decreasing PVD spacing. By laboratory tests, Wang et al. [12] proved that the larger 
the spacing between drainage plates, the slower the consolidation rate. Zhou et al. [13] proposed analytical solutions to axisymmetric consolidation of a multilayered ground. The solutions reveal that the consolidation rate is accelerated when the spacing of PVDs is closer. Basu and Prezzi [14, 15] found that if the soil disturbance is considered in the calculation, the estimated increase in consolidation rate obtained by reducing the PVD spacing is not much greater than the actual increase in the soil disturbance caused by PVD installation.

The references above focus mainly on treatment effects of the naturally deposited soil. Generally, it is concluded that the PVD spacing is only controlled by the desired consolidation rate, which implies that the treatment effect associated with larger PVD spacing will eventually be the same as that of smaller spacing, given the treatment time is long enough. However, this might not be true for the dredged slurry ground treated by vacuum preloading, due to the inherent clogging phenomenon. As will be clarified in the main text, our field test shows that not only the consolidation rate but also the final settlement and the PWP dissipation associated with larger PVD spacing are less than those of the close spacing case.

In this article, three neighboring slurry foundations incorporating different PVD spacing were selected to conduct the field tests on vacuum treatment effects. The settlement and the PWP dissipation were monitored during the treatment. Moreover, three finite element models incorporating different patterns of vacuum attenuation along the PVD were established to reproduce the vacuum preloading processes of the three tested slurry foundations. The simulated and tested results generally agree, which helps clarifying the influence of PVD spacing on vacuum treatment effects of dredged slurry.

\section{Field Test}

2.1. Background. The test site is located at eastern Taizhou, a coastal city of China, as shown in Figure 1. The site, originally as a tideland, was reclaimed by dredging seabed sediments into a cofferdam. According to the city planning, the reclaimed site is going to be municipal lands, e.g., wetland scenes and coastal roads, as can be seen in Figure 2. After the dredging operations, the site was left to rest for about half a year. Then, the site investigation was carried out, and slurry soil samples were taken for laboratory tests on basic properties, as given in Table 1. It is seen that on top of the original tideland clay, there are two layers of dredged slurry with total thickness $7 \mathrm{~m}$. The water content of the first layer (of thickness $1 \mathrm{~m}$ ) is slightly below the liquid limit, which is due to the water evaporation during the resting period. For the second slurry layer, it is noted that the water content of the slurry is about 1.5 times its liquid limit, which implies that the slurry particles are generally in the loose/ none contact status. The gradation curve in Figure 3 shows that the dredged slurry is mainly composed of silt and clay particles.

The slurry foundation has to be improved before to serve as the municipal land. A new version of the vacuum

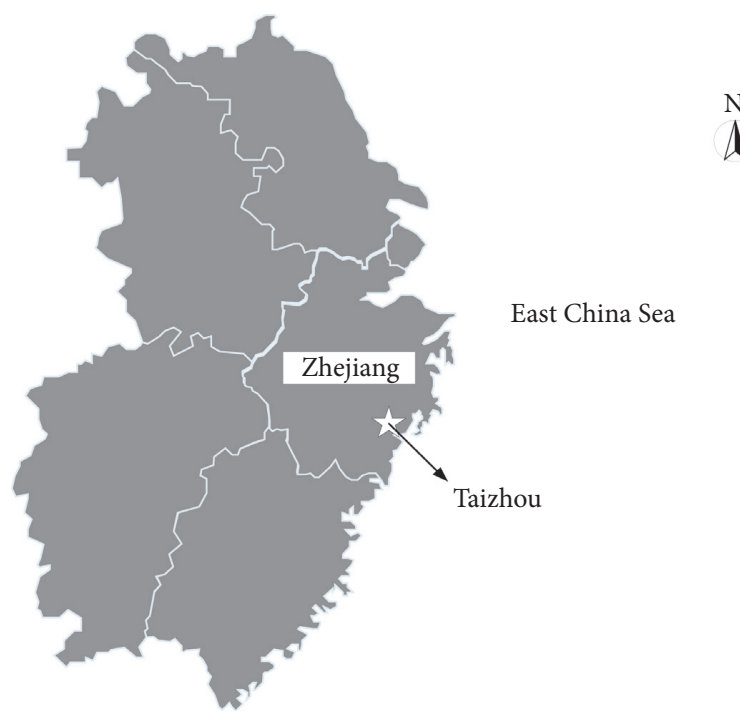

$\stackrel{N}{4}$

Figure 1: Location of Taizhou.

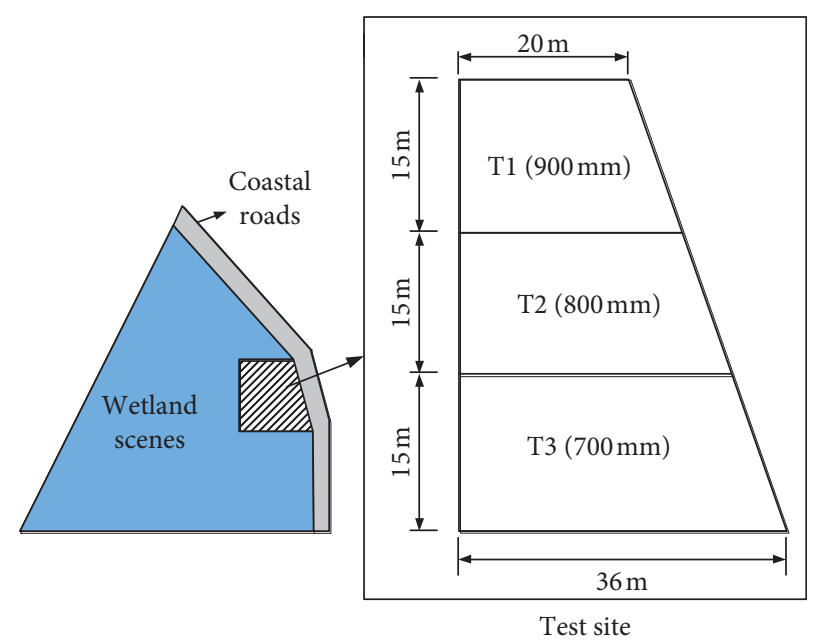

Figure 2: Location of test area.

preloading technique is adopted for the treatment. An airtight hose is used to conduct the vacuum to PVD via a hand connector [1] so that the sand blanket in conventional techniques can be cancelled. Two layers of airtight geomembranes are placed on top of the foundation to seal it from the atmosphere. Along the edges of the treated area, the geomembranes are anchored about $0.5 \mathrm{~m}$ into the ground to ensure the airtightness of the whole system.

According to the design documents, the PVDs are inserted $7 \mathrm{~m}$ into the ground to penetrate the dredged slurry. The PVDs are arranged in square grid with spacing $700 \mathrm{~mm}$. Sectional dimensions of the PVD band are $100 \mathrm{~mm}$ (width) $\times 4 \mathrm{~mm}$ (thickness). The designed vacuum pressure and treatment period are $85 \mathrm{kPa}$ and 120 days, respectively.

2.2. Test Setup. As shown in Figure 2 , the test site consists of three foundations of different areas, which are numbered as T1, T2, and T3, respectively. The PVD spacing of T3 is the same as the original design, i.e., $700 \mathrm{~mm}$. In order to 
TABLe 1: Physical properties of different soil layers at the test site.

\begin{tabular}{|c|c|c|c|c|c|c|c|c|c|}
\hline Layer & $\begin{array}{l}\text { Depth } \\
(\mathrm{m})\end{array}$ & $\begin{array}{c}\text { Water } \\
\text { content, } w \\
(\%)\end{array}$ & $\begin{array}{l}\text { Liquid } \\
\text { limit, } W_{\mathrm{L}} \\
(\%)\end{array}$ & $\begin{array}{c}\text { Plastic } \\
\text { limit, } W_{\mathrm{P}} \\
(\%)\end{array}$ & $\begin{array}{c}\text { Specific } \\
\text { gravity of soil } \\
\text { grain } G_{s}\end{array}$ & $\begin{array}{c}\text { Initial } \\
\text { void ratio } \\
e_{0}\end{array}$ & $\begin{array}{l}\text { Void ratio at } \\
100 \mathrm{kPa} e_{100}\end{array}$ & $\begin{array}{c}\text { Horizontal } \\
\text { permeability } \\
\text { coefficient } \\
(\mathrm{m} / \mathrm{s})\end{array}$ & $\begin{array}{l}\text { Coefficient of } \\
\text { compressibility } \\
\left(\mathrm{MPa}^{-1}\right)\end{array}$ \\
\hline $\begin{array}{l}\text { Dredged } \\
\text { slurry \#1 }\end{array}$ & $0-1$ & 34.9 & 39.4 & 23.8 & 2.72 & 0.95 & 0.81 & $5 e-9$ & 0.53 \\
\hline $\begin{array}{l}\text { Dredged } \\
\text { slurry \#2 }\end{array}$ & $1-7$ & 50.2 & 38.1 & 23.7 & 2.75 & 1.38 & 1.00 & $6 e-9$ & 0.86 \\
\hline Muddy clay & $7-14$ & 55.8 & 41.8 & 23.7 & 2.74 & 1.53 & 1.26 & $2 e-9$ & 0.52 \\
\hline
\end{tabular}

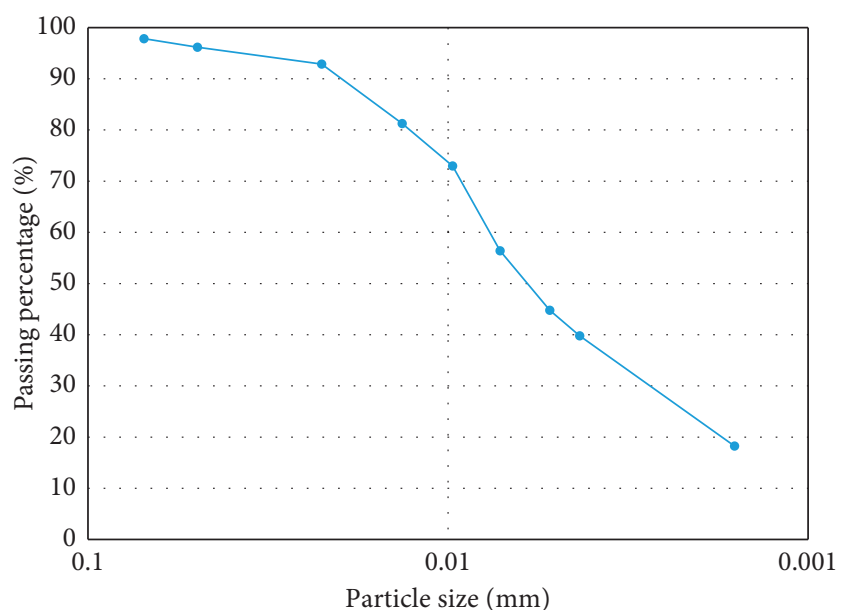

Figure 3: Grain size distribution curve of the slurry.

investigate the influence of PVD spacing on treatment effects, two more spacing 800 and $900 \mathrm{~mm}$ are assigned to T2 and T1, respectively. The PVDs of the three foundations are of the same burying depth (i.e., $7 \mathrm{~m}$ ) and of the same layout pattern (i.e. square grid). The three tested foundations share the same geomembrane and vacuum pump, so the vacuum pressures are the same. Because the three foundations are of relatively small area $\left(540 \mathrm{~m}^{2}\right.$ to the largest) and neighboring to each other, spatial variations on properties of the dredged slurry are considered to be neglectable. In total, the field tests are controlled so that the PVD spacing would be the leading (if not only) factor governing the comparisons on treatment effects.

2.3. Layout of Monitoring Points. In order to assess the treatment effects, the settlement plate, the PWP transducer, and the layered-settlement pipe are adopted to monitor the surface settlement, the PWP dissipation, and the layered settlement, respectively, during the treatment period. Layout of the monitoring points is given in Figure 4. It is seen that two groups of monitoring points are set for each foundation. One is at the geometrical center; the other is at the right-bottom corner. For each group, the settlement plate and the layered-settlement pipe are shifted $3 \mathrm{~m}$ horizontally and vertically relative to the PWP monitoring point. It is seen that, from Figure 4, the three types of monitoring points are all at the center of the square grid.
For the PWP monitoring point, there are three PWP transducers located at $1 \mathrm{~m}, 4 \mathrm{~m}$, and $7 \mathrm{~m}$, respectively, below the ground surface. The effective range and resolution of the PWP transducer is $-0.1-0.1 \mathrm{MPa}$ and $0.08 \mathrm{kPa}$, respectively. For the layered settlement, three magnetic rings are slipped onto the settlement pipe to reach their initial locations at $-1 \mathrm{~m},-3 \mathrm{~m}$, and $-5 \mathrm{~m}$, respectively. Because the rings settle along with the soil, the layer settlement can be determined from their real-time locations during the treatment period. It is noted that the bottom of the settlement pipe enters $1 \mathrm{~m}$ into the muddy clay layer, which guarantees no settlement would happen to the pipe itself. The vertical profile of the monitoring points is schematically shown in Figure 5.

\section{Test Results and Discussion}

The design documents require that the vacuum preloading can be terminated upon satisfactions of the following: (1) the treatment time reaches 120 days; (2) the average consolidation degree is larger than 65\%; and (3) the surface settlement rate is less than $3 \mathrm{~mm}$ /day for 10 consecutive days. In our test, the treatment time is elongated to 180 days to ensure that the three test foundations have reached the final and stable status.

Because there are two groups of monitoring points for each test foundation (see Figure 4), the values from them are averaged to perform comparisons in the following context.

3.1. Surface Settlement. The comparison on the surface settlement between T1, T2, and T3 is shown in Figure 6. It is seen that the settlement develops quickly after the application of the vacuum pressure. However, rebounds are observed for the three settlement curves around $t=87 \mathrm{~d}$ before they finally become stable. The rebound happens due to the loss of vacuum pressure as a result of the electricity failure.

For the period before the rebound, the settlement rate of $\mathrm{T} 2$ is the larger than that of T1, and T3's rate is larger than T2 in turn. The observation is within expectation because the PVD spacing of $\mathrm{T} 1$ is the largest. When the power is regained, the amount of rebound is compensated soon by recompression of the soil under the vacuum pressure. Thereafter, the stable settlement of T3 is about $5 \mathrm{~cm}$ larger than that of T2; and T1's settlement is obviously the smallest. As can be seen From Figure 7, the settlement rate of T2 and T3 is obviously larger than that of T1 during the early stage of the treatment (i.e., 0-20 d); however, during the last 32 days 


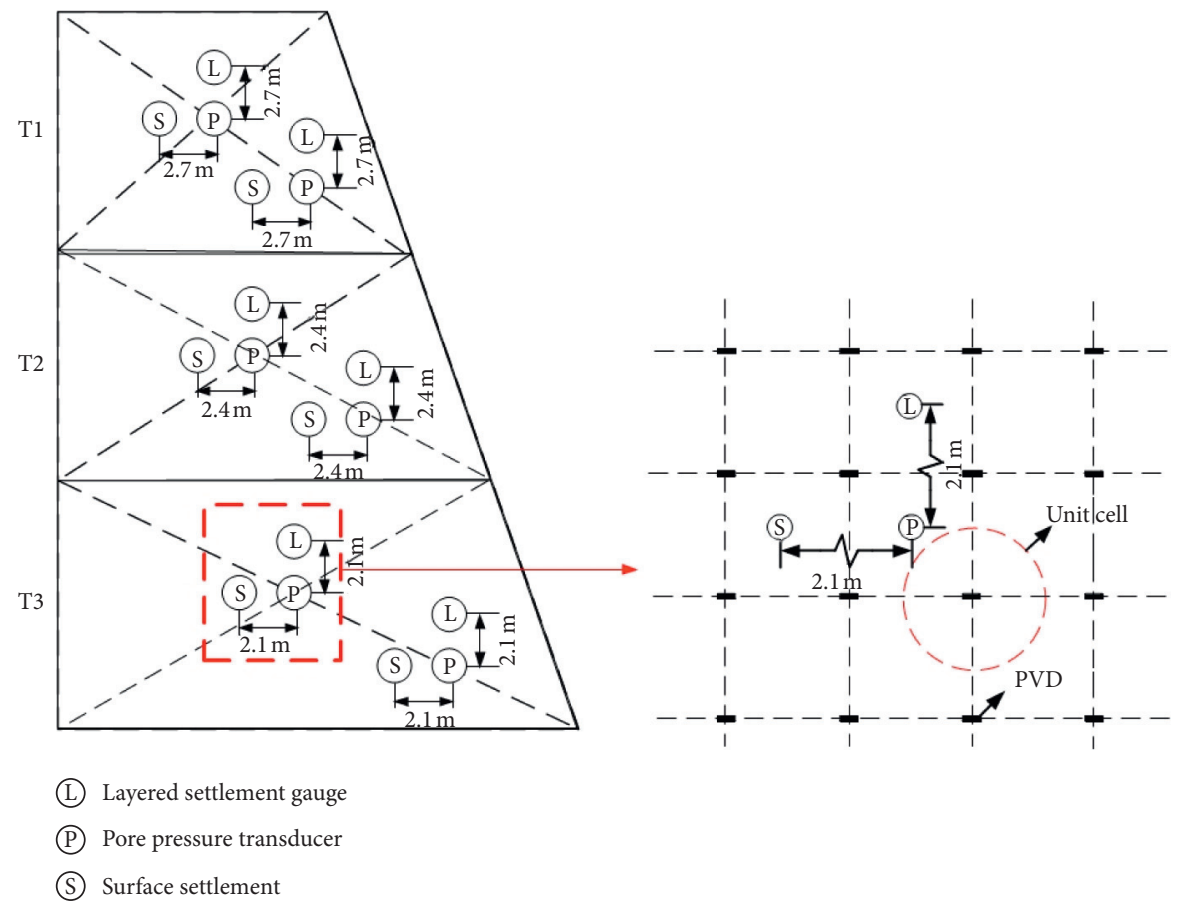

FIGURE 4: Layout of monitoring points.

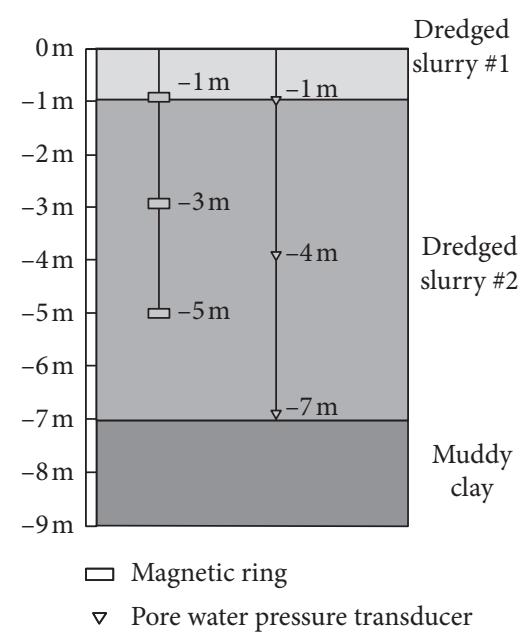

FIgURE 5: Elevation view of installed instruments layout.

of the treatment, the settlement rates of the three test foundations are close to each other, and more importantly, they are smaller than $3 \mathrm{~mm} /$ day. The observation implies that their settlement has reached the final and stable values. It is noted that the final settlement of $\mathrm{T} 1$ is about $4.6 \mathrm{~cm}$ and $12.93 \mathrm{~cm}$ smaller than that of T2 and T3, respectively. The comparison clarifies that enlarging PVD spacing influences not only the settlement rate but also the amount of final settlement.

3.2. Pore-Water Pressure. The comparisons on PWP dissipation between the three test foundations are shown in Figure 8. It is noticed that the initial PWP values at different depth is about $10-20 \mathrm{kPa}$ higher than the corresponding hydrostatic pressure. For example, at $t=0$, the PWP reading from the transducer at $-1 \mathrm{~m}$ of $\mathrm{T} 2$ is $17 \mathrm{kPa}$, which is $7 \mathrm{kPa}$ higher than the hydrostatic pressure $10 \mathrm{kPa}$ (the groundwater table is at the surface). This observation means the water is confined in the dredged slurry and thus implies that the slurry particles could be in a suspension status, as mentioned in Section 2.1. In the natural condition, the excess pressure would dissipate very slowly because the drainage can only happen through the top surface. However, the drainage is facilitated after installations of the PVDs. As can be seen from Figure 8, the PWP at different depth dissipates $1 \sim 3 \mathrm{kPa}$ during the first 27 days even without the application of vacuum pressure.

When the vacuum pressure is applied, the PWP dissipates steadily. Table 2 compares the final PWP dissipation during the vacuum preloading period between the three test foundations. It is seen that the PWP dissipations generally decrease with the increasing of the burying depth. It is within expectation because the vacuum pressure attenuates along the PVD depth due to the well-resistance effect. It is observed that the PWP dissipation of $\mathrm{T} 3$ is $5.77 \mathrm{kPa}, 5.61 \mathrm{kPa}$, and $1.94 \mathrm{kPa}$ higher than that of T2 at $-1 \mathrm{~m},-4 \mathrm{~m}$, and $-7 \mathrm{~m}$, respectively. Also, the PWP dissipation of T3 is $9.31 \mathrm{kPa}, 8.62 \mathrm{kPa}$, and $3.2 \mathrm{kPa}$ higher than that of T1. The comparison clearly demonstrates that enlarging the PVD spacing would increase the vacuum attenuation along the PVD depth. Hence, the final PWP dissipation of the dredged slurry would be decreased.

3.3. Layered Settlement. Figure 9 presents comparisons on layered settlement between the three test foundations. From the figure, it is seen that the development of layered 


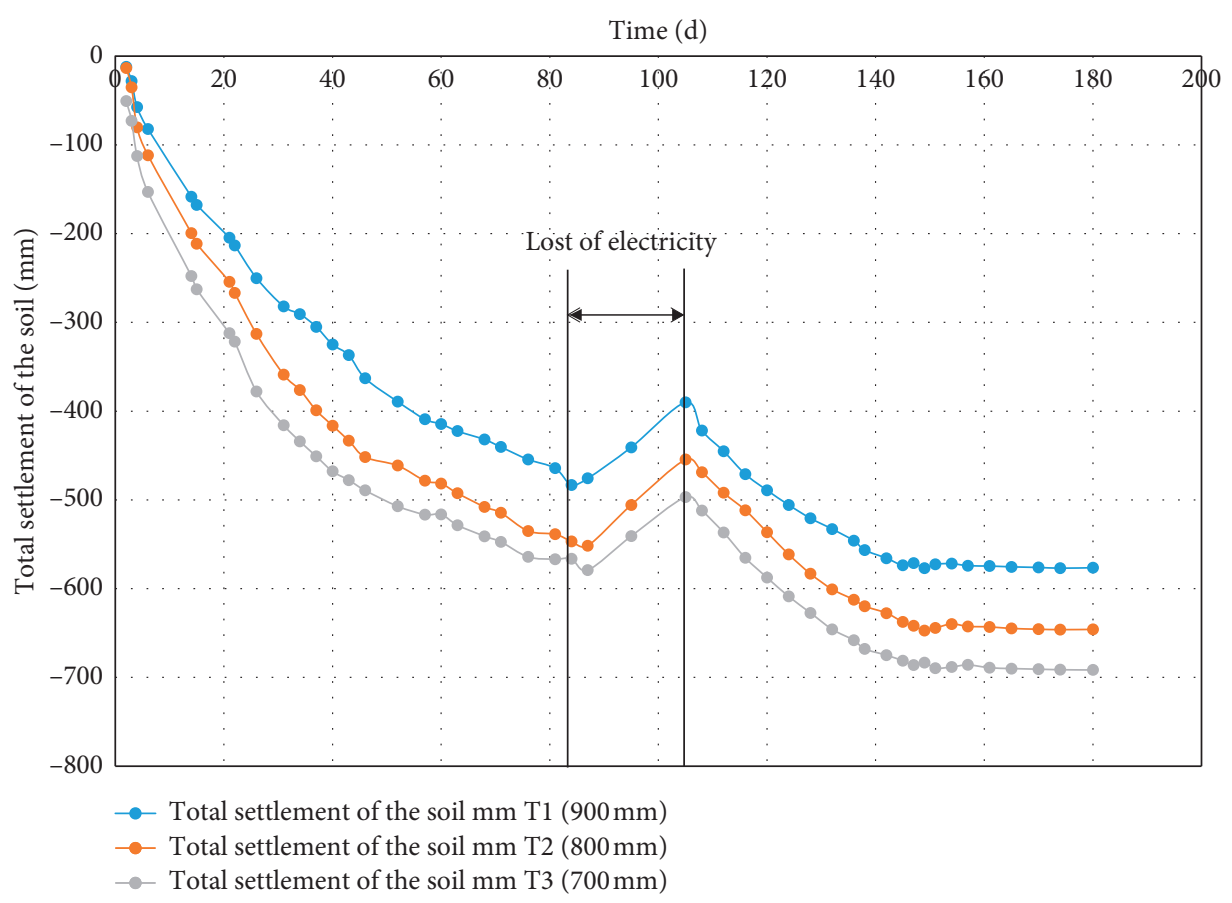

FIgURE 6: Surface settlements for the three zones.

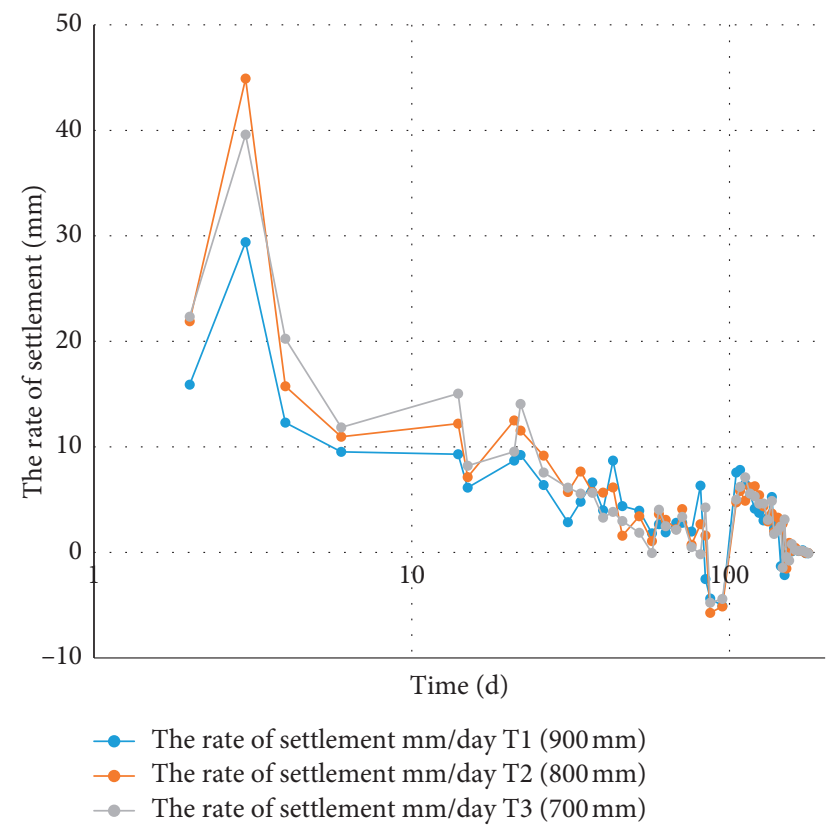

FIgURE 7: Rate of surface settlement.

settlement during the treatment generally resembles that of the surface settlement presented in Figure 6. The final settlements at different depths are summarized in Table 3 for the three test foundations. It is observed that the value of final settlement decreases significantly with the increasing depth, which again, together with the observation in Figure 8 , demonstrates the existence of vacuum attenuation along the PVD depth.

The difference between the settlements associating with neighboring magnetic rings gives the compression of the soil layered between the two rings. For example, the compression of the soil within $-1 \mathrm{~m}$ and $-3 \mathrm{~m}$ of $\mathrm{T} 1$ can be calculated by subtracting the settlement at $-3 \mathrm{~m}$ from that at $-1 \mathrm{~m}$, which gives $250.1 \mathrm{~mm}$. Similarly, the compressions of slurry layers at other depth can be determined, and they are included in Table 3. Larger amount of compression can be observed for slurry at depths from $-1 \mathrm{~m}$ to $-3 \mathrm{~m}$ and from $-3 \mathrm{~m}$ to $-5 \mathrm{~m}$ when compared with other depths, i.e., 0 to $-1 \mathrm{~m}$ and -5 to $-7 \mathrm{~m}$. The top layer $(0 \sim-1 \mathrm{~m})$ is less compressed because it is subjected to more evaporation and thus becomes stiffer, as indicated in Table 1 .

When the soil compressions of $\mathrm{T} 1$ are compared with those of T2 and T3, it is found that the compression of the soil layered between $-1 \mathrm{~m}$ and $-3 \mathrm{~m}$ of $\mathrm{T} 1$ is about 39 and $58 \mathrm{~mm}$ lower than that of T2 and T3, respectively. Also, it is observed that the compression of slurry layered between $-3 \mathrm{~m}$ and $-7 \mathrm{~m}$ of $\mathrm{T} 1$ is obviously smaller than that of $\mathrm{T} 2$ and T3. Again, the comparison demonstrates that the vacuum attenuation should be more severe in the case of larger PVD spacing.

3.4. Test Results Discussion. Hansbo [16] had developed series of analytical solutions to the consolidation problem of soft soil with PVD. The PVD spacing is introduced into the solution through a dimensionless parameter $n=D / d$, where $D$ and $d$ are the equivalent diameters of the soil cylinder and the PVD section, respectively. It is noted that $D$ depends on both the PVD spacing $l$ and the PVD grid pattern, e.g. $D=1.13 l$ for square grid. When the wellresistance and the smear effects are not considered, Hansbo's analytical solution to the average consolidation degree and the average consolidation rate reads as follows: 


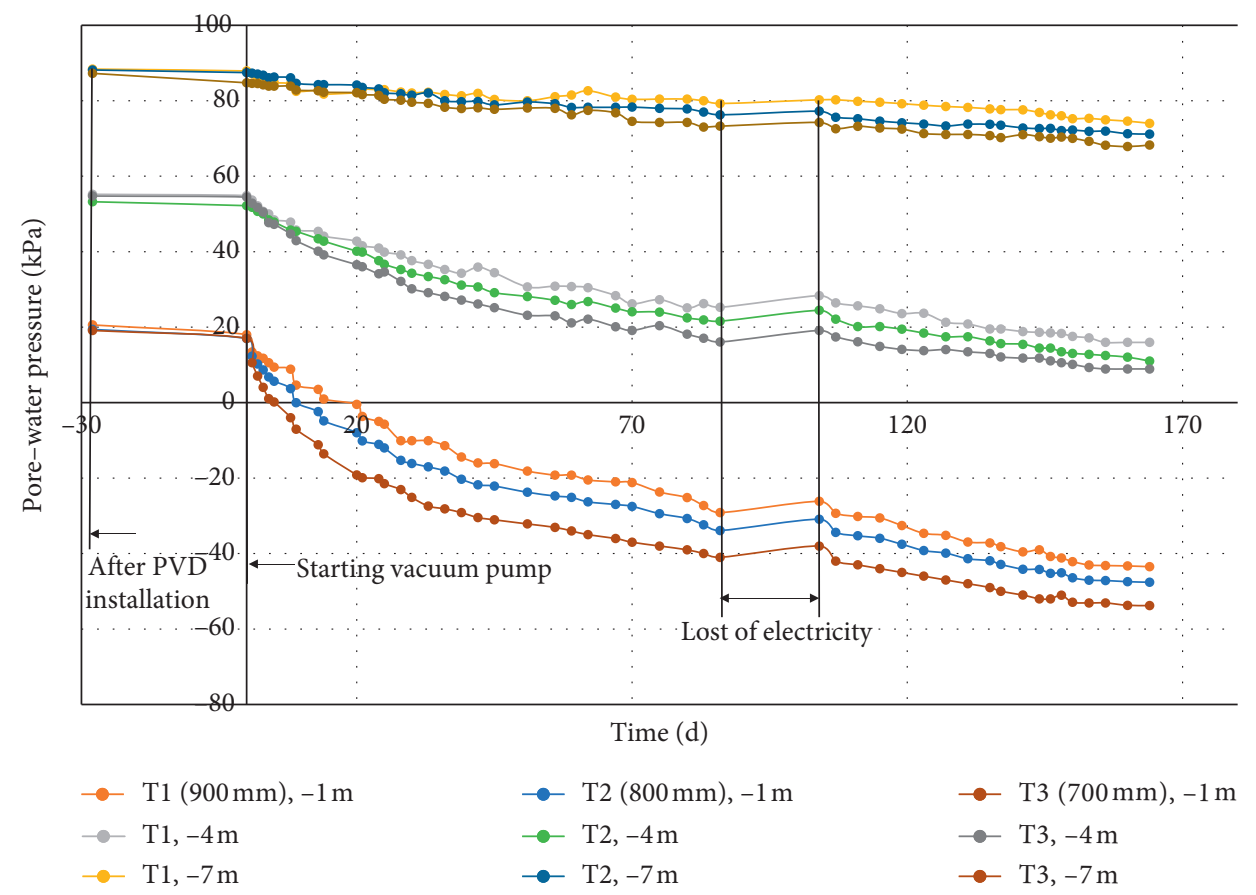

Figure 8: Variations of pore water pressure at different depths.

TABLE 2: Final PWP dissipations during vacuum preloading period.

\begin{tabular}{lccc}
\hline $\begin{array}{l}\text { Depth } \\
(\mathrm{m})\end{array}$ & $\begin{array}{c}\text { T1 }(900 \mathrm{~mm}) \\
(\mathrm{kPa})\end{array}$ & $\begin{array}{c}\text { T2 }(800 \mathrm{~mm}) \\
(\mathrm{kPa})\end{array}$ & $\begin{array}{c}\text { T3 }(700 \mathrm{~mm}) \\
(\mathrm{kPa})\end{array}$ \\
\hline-1 & 59.58 & 63.12 & 68.89 \\
-4 & 39.21 & 42.22 & 47.83 \\
-7 & 15.32 & 16.58 & 18.52 \\
\hline
\end{tabular}

$$
\left\{\begin{array}{l}
\bar{U}=1-\exp \left[\frac{-\left(8 c_{h} t / d^{2}\right)}{n^{2} \mu_{0}}\right] \\
\frac{\mathrm{d} \bar{U}}{\mathrm{~d} t}=\frac{8 c_{h} / d^{2}}{n^{2} \mu_{0}} \exp \left[\frac{-\left(8 c_{h} t / d^{2}\right)}{n^{2} \mu_{0}}\right]
\end{array}\right.
$$

where $\mu_{0}=\ln n-0.75 ; c_{h}$ is consolidation coefficient and $t$ is time. It is clear from the second equation that the consolidation rate would be decreased when the PVD spacing is enlarged, as shown in Figure 10(a). However, as can be seen from the first equation (Figure 10(b)), the average consolidation degrees associating with different PVD spacing should be eventually the same given the treatment time is long enough, i.e. $\cup \longrightarrow 1_{\text {at }}$ at $t \longrightarrow \infty$. The above observations still apply when the effects of well-resistance and smear effects are taken into account. Actually, only the denominators of the right-hand term in Equation (1) need to be changed into $n^{2} \mu s$, where $\mu_{s}=\mu_{0}+\mu_{a}$ and $\mu_{a}$ is an additional parameter accounting for the smear and well-resistance effects.

However, the test results in Sections 3.1-3.3 show that not only the consolidation rate has been lowered but also the values of final settlements and PWP dissipations are decreased, when a larger PVD spacing is adopted. This observation could not be explained by the above analytical solutions because they are developed for naturally deposited soils. Although for the dredged slurry, the slurry particles are initially suspended by the excess pore water pressure. The particles will migrate towards and then accumulate around the PVD membrane, forming a so-called clogging zone. The clogging effect that is inherent to vacuum consolidation of slurry via PVD should be the main reason of the observed discrepancy between the classical theory predictions and the field test observations. The in-depth discussions on how the clogging effects are related to the vacuum attenuation shall be the topic of another paper. Here, we focus on demonstrating how to phenomenologically reproduce the field observations by considering both the vacuum attenuation along PVD and the clogging zone in the numerical models, as will be shown in section 4 .

\section{Numerical Simulation}

From the above discussions on the test results, it is understood that, for reasonably reproducing the vacuum consolidation process, two leading factors should be included in the numerical model: (1) vacuum attenuation along the PVD depth and (2) geometry, compressibility, and permeability characteristics of the clogging zone. The former determines the upper limit of the PWP that could be dissipated at different depths of the slurry. The latter tells how fast this limit would be reached.

4.1. Vacuum Pressure Attenuation along PVD. Existing field tests have already revealed that the vacuum pressure may decrease with depth when it is applied through PVDs [17-19]. Indraratna [20] indicated that the distribution of 


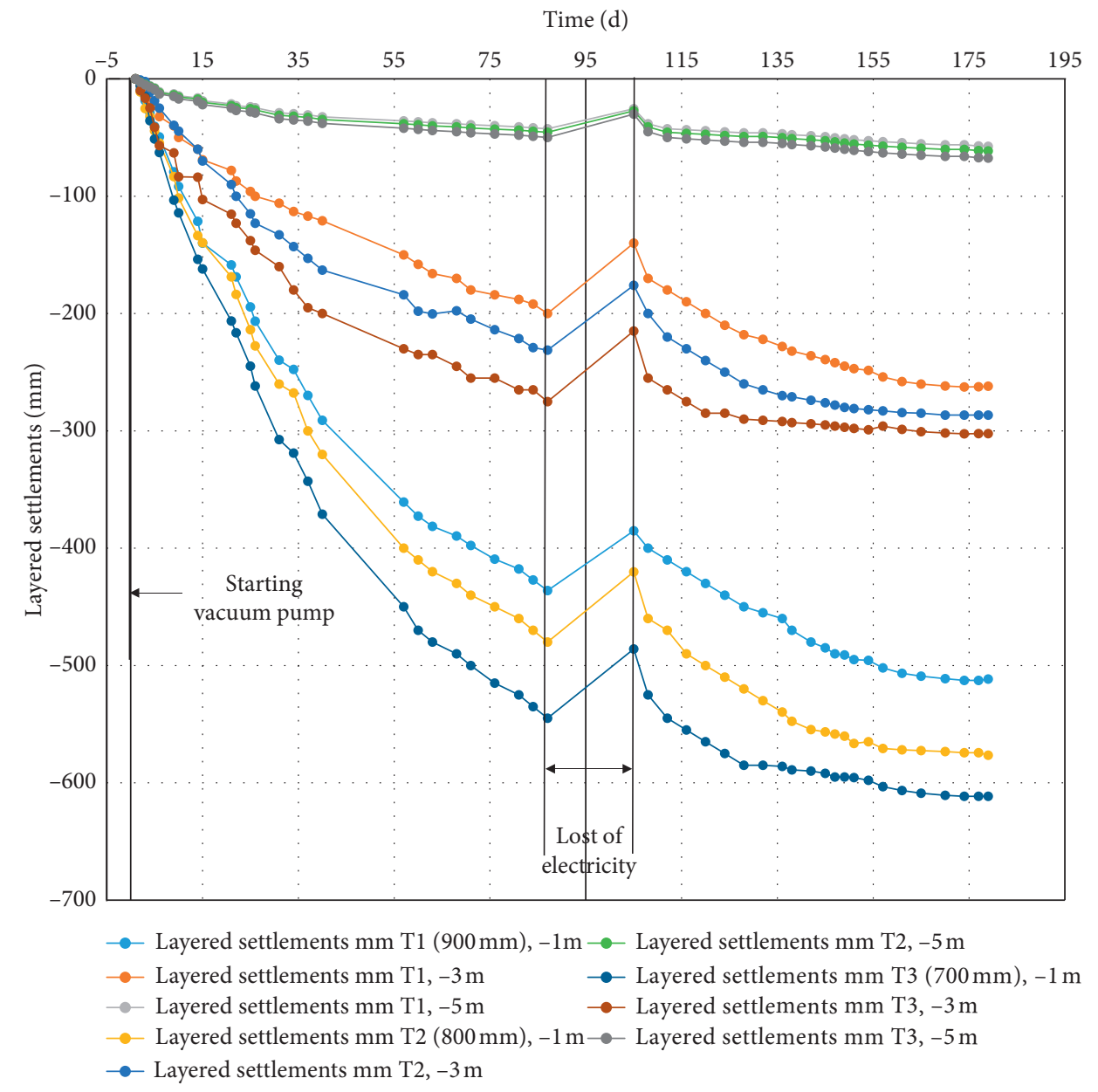

Figure 9: Layered settlements at different depths.

TABLE 3: Layered settlements and compressions.

\begin{tabular}{lccc}
\hline & Depth $(\mathrm{m})$ & Layered settlement $(\mathrm{mm})$ & Unit compression $(\mathrm{mm} / \mathrm{m})$ \\
\hline & 0 & 576.4 & - \\
T1 $(900 \mathrm{~mm})$ & -1 & 512.7 & 63.7 \\
& -3 & 262.6 & 125.05 \\
& -5 & 57.5 & 102.55 \\
& -7 & - & 28.75 \\
\hline & 0 & 645.9 & - \\
T2 $(800 \mathrm{~mm})$ & -1 & 574.6 & 71.3 \\
& -3 & 285.5 & 144.55 \\
& -5 & 63.1 & 111.2 \\
& -7 & - & 31.55 \\
T3 $(700 \mathrm{~mm})$ & 0 & 691.6 & - \\
& -1 & 611.5 & 80.1 \\
& -3 & 303.7 & 153.9 \\
& -5 & 67.5 & 118.1 \\
\end{tabular}


vacuum pressure along the drain length depends both on the sealing and the type of soil around the drain. The attenuation rate is generally reported to be $10-11 \mathrm{kPa} / \mathrm{m}$ for PVD
[21, 22]. A formula has been proposed by Zhang et al. [23] to convert the PWP dissipation into the vacuum degree:

$$
P=\frac{1}{2}\left[P_{w}-y_{w} \Delta S+P_{0}+y_{w} L_{0}-\sqrt{\left(P_{w}-y_{w} \Delta S+P_{0}+y_{w} L_{0}\right)^{2}-4\left(P_{w}-y_{w} \Delta S\right) P_{0}}\right.
$$

where $P$ is absolute value of the vacuum pressure of PVD; $P_{w}$ is PWP dissipation; $P_{0}$ is $1 \mathrm{~atm} ; \gamma_{w}$ is unit volumetric weight of water; $\Delta s$ is the ground settlement; and $L_{0}$ is the distance between the initial groundwater table and the ground surface. In addition, the pore pressure at $0 \mathrm{~m}$ is $-85 \mathrm{kPa}$.

To keep in line with the existing researching [13, 20, 24-27], a linear distribution of vacuum pressure along the PVD depth is adopted. Taking T1 as an example, substituting the PWP dissipation at $-7 \mathrm{~m} p_{w}=7.68 \mathrm{kPa}$ and the ground settlement $\Delta s=0.576 \mathrm{~m}$ into equation (2), the vacuum pressure at bottom end of the PVD can be calculated as $P=1.83 \mathrm{kPa}$. Thus, a linear distribution from $P=85 \mathrm{kPa}$ at the top to $P=1.83 \mathrm{kPa}$ at the bottom of PVD can be obtained, as shown in Figure 11. Similarly, the vacuum pressure distribution associated with test foundation $\mathrm{T} 2$ and T3 can be obtained.

4.2. Formation of Clogging Zone. A series of laboratory tests have been conducted to characterize the temporal and spatial variations of the clogging zone that would be formed during vacuum treatment of dredged slurry. The test involves a steel barrel holding the dredged slurry and a PVD embedded along the barrel axis. The PVD is of section size $10 \mathrm{~cm} \times 0.5 \mathrm{~cm}$ (width $\times$ height) and of permeability $>5 \times 10^{-5} \mathrm{~m} / \mathrm{s}$. The barrel size is of $0.8 \mathrm{~m} \times 0.4 \mathrm{~m}$ (height $\times$ radius). The vacuum pressure of $-85 \mathrm{kPa}$ is applied through a moisture separator and a tube connecting to the PVD. The separator collects the drained water, through which the drainage rate can be determined. For details of the model test, one is referred to the article by Zhou et al. [28], here, we only present results that are relevant to present study.

The results showed that the drainage rate drops about 85\% during the first 1440 minutes and drops further from $0.003 \mathrm{~L} / \mathrm{min}$ to $0.0005 \mathrm{~L} / \mathrm{min}$ in the following 4320 minutes. After 5760 minutes, the drainage rate changes slightly with the consolidation time. The comparison between the drainage rate of the periods before and after 5760 minutes reveals that a clogging zone has been formed around the PVD within the first 5760 minutes.

The test is suspended when the clogging zone has formed so that soil samples can be taken from the barrel at different radial distances from its axis (i.e. the PVD). The samples are used for laboratory tests on the permeability and water content. The results showed that the water content $(w)$ increases with the radial distance from the PVD. Obvious dropping in water content (i.e., $w / w_{L}$ drops from 1.41 to 0.69 ) can be observed for soils within $7 \mathrm{~cm}$ of the radial distance, which indicates that the void ratio decreases significantly and thus a dense soil layer (i.e., clogging zone of reduced void ratio $e_{c 0}$ ) is formed within this range. Moreover, from the permeability curve, it is seen that the permeability of the clogging zone $\left(k_{c 0}\right)$ is about $1 / 300$ of $k_{0}$. The drop in water content and permeability demonstrates the formation of a clogging zone (i.e., a dense soil layer of cylinder shape with the PVD along its axis) whose radius is about $7 \mathrm{~cm}$.

Because the time interval (0-5760 mins) required for the formation of clogging zone is considerably short when compared with the treatment period (e.g. $120 \mathrm{~d}$ ), the formation process of the clogging zone itself would not be the focus and thus will not be reproduced in the following numerical studies. Instead, a preexisting clogging zone of varying radius ( $7 \mathrm{~cm}$ at the PVD top and zero at the PVD tip) along with reduced permeability (i.e., $k_{c 0}=k_{0} / 300$ ) is assumed for following finite element models.

4.3. Compressibility and Permeability of Slurry Soil. When the consolidation processes, the compressibility and permeability of the soil within and without the clogging zone would be subjected to change, a logarithmic function [29-33] is adopted for describing the nonlinear variation of permeability with respect to void ratio,

$$
\log k=\log k_{i}+\left(\frac{\theta-\theta_{1}}{C_{k}}\right),
$$

where $k$ is the soil permeability; $C_{k}$ is permeability index; $e_{i}$ is the initial void ratio, and $k_{i}$ is the initial permeability. For the soil within the clogging zone, $e_{i}=e_{c 0}$ and $k_{i}=k_{c 0}$, whereas for the soil outside, $e_{i}=e_{0}$ and $k_{i}=k_{0}$.

The porous elastic model provided by ABAQUS is adopted for governing the constitutive deformation behavior of the slurry, i.e.,

$$
\Delta e=M \ln \left(\frac{p}{p o}\right),
$$

where $\Delta e$ is the change of void ratio of soil $\left(\Delta e=e_{0}-e\right) ; M$ is the Log bulk modulus; $p_{0}$ is initial average stress.

4.4. Finite Element Model. The arrangement pattern of PVDs in the field can be deemed as repetitions of a unit cell (see Figure 4) that is composed by a soil cylinder and a PVD embedded along its axis. Three finite element models of different cylinder radius are established to model the vacuum consolidation of the dredged slurry. The cylinder radius $r_{e}$ depends on the PVD spacing $l$ by 


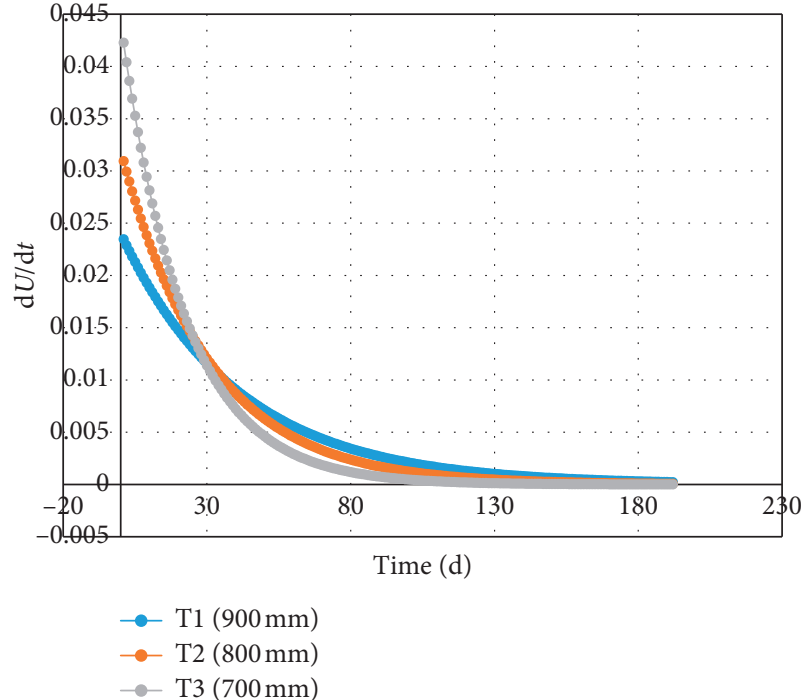

(a)

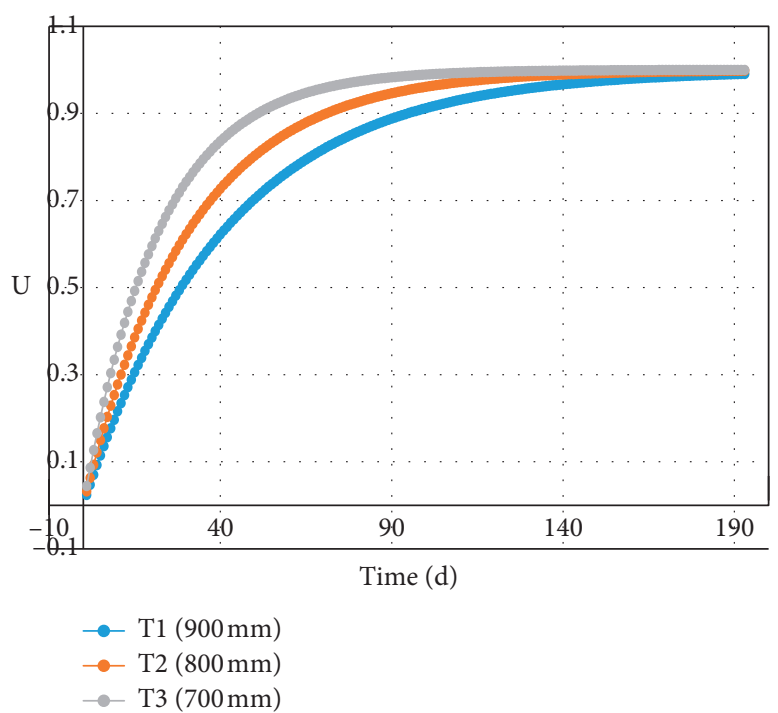

(b)

Figure 10: (a) Consolidation rate; (b) Average degree of consolidation.
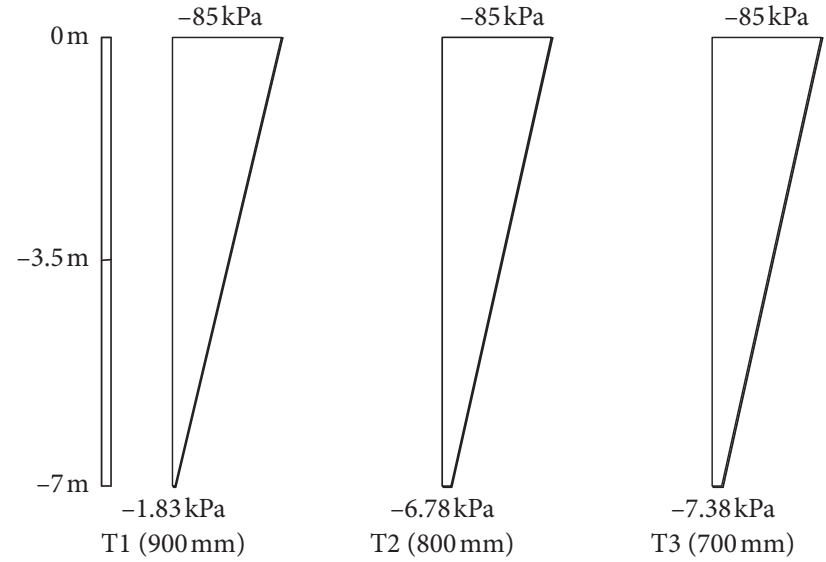

FIGURE 11: Vacuum pressure distribution along PVD.

$r_{e}=0.569 l$ when the square grid is adopted for PVD arrangements (see Figure 4). The PVD is not explicitly included in the model. Instead, it is functionally replaced by a hollow cylinder of radius $r_{w}$. The equivalent radius $r_{w}$ of a band-shaped PVD can be calculated by $r_{w}=(W+T) / 4$, where $W$ and $T$ are the width and thickness of the PVD section, respectively. Geometric dimensions of the three finite element models are summarized in Table 4.

Axisymmetric $2 \mathrm{D}$ mesh is used for discretizing the soil cylinder, as shown in Figure 12. The bottom boundary is restrained from any movement. The right side boundary is restrained from horizontal movement, and an axisymmetric boundary condition is applied for the left side boundary. The top, bottom, and peripheral boundaries are set as impermeable.

A cone volume surrounding the PVD is assigned to be the clogging zone, whose radius is set to decreases linearly from $7 \mathrm{~cm}$ to $0 \mathrm{~cm}$ along with the depth. Constitutive parameters of the soil within and outside of the clogging zone are summarized in Table 5.

The vacuum pressure shown in Figure 11 is specified by the negative pore pressure boundaries along the PVD length. Gravity load is set in the whole model. The initial pore pressure of soil is 0 . The vacuum pressure is applied after the geostatic equilibrium step. The period for vacuum consolidation is set to more than 360 days to guarantee adequate development of treatment effects. The settlement and PWP dissipation are monitored for the simulation and then used for comparisons in the following. The points where the simulation results of the pore water pressure are extracted have been marked in the model. The simulation results on settlement are taken as the averaged settlement weighted over the top surface of the soil model.

4.5. Simulation Results and Discussion. The comparisons on the treatment effects (including the surface settlement, the layered settlement, and the PWP development) between the simulations results and test data are shown in Figure 13. To save pages, the comparison is conducted only for the test foundation T2. It is seen that both the development trend and the final results of the model simulation of surface settlement, pore pressure, and layered settlement are consistent with the data provided by the field test. The above comparison validates the developed finite element simulations.

In order to guarantee adequate development of treatment effects, the treatment time is elongated to $360 \mathrm{~d}$ in the numerical simulation. This is a case that can only be realized in the numerical simulation because in real practice, the financial budget and tight time schedule would prohibit the doubling of the treatment time (i.e. from $180 \mathrm{~d}$ to $360 \mathrm{~d}$ ). The comparisons on surface settlement between the three test foundations are shown in Figure 14. It is noticed that the settlement of the three foundations develop quickly during 
TABLE 4: Dimensions of finite element models.

\begin{tabular}{lcccc}
\hline Name & PVD radii $r_{w}(\mathrm{~mm})$ & PVD depth $(\mathrm{m})$ & Soil cylinder radii $r_{e}(\mathrm{~mm})$ & Soil cylinder height $(\mathrm{m})$ \\
\hline Model-1 & 31.4 & 7 & 719.02 & 9 \\
Model-2 & 31.4 & 7 & 639.13 & 9 \\
Model-3 & 31.4 & 7 & 559.24 & 9 \\
\hline
\end{tabular}

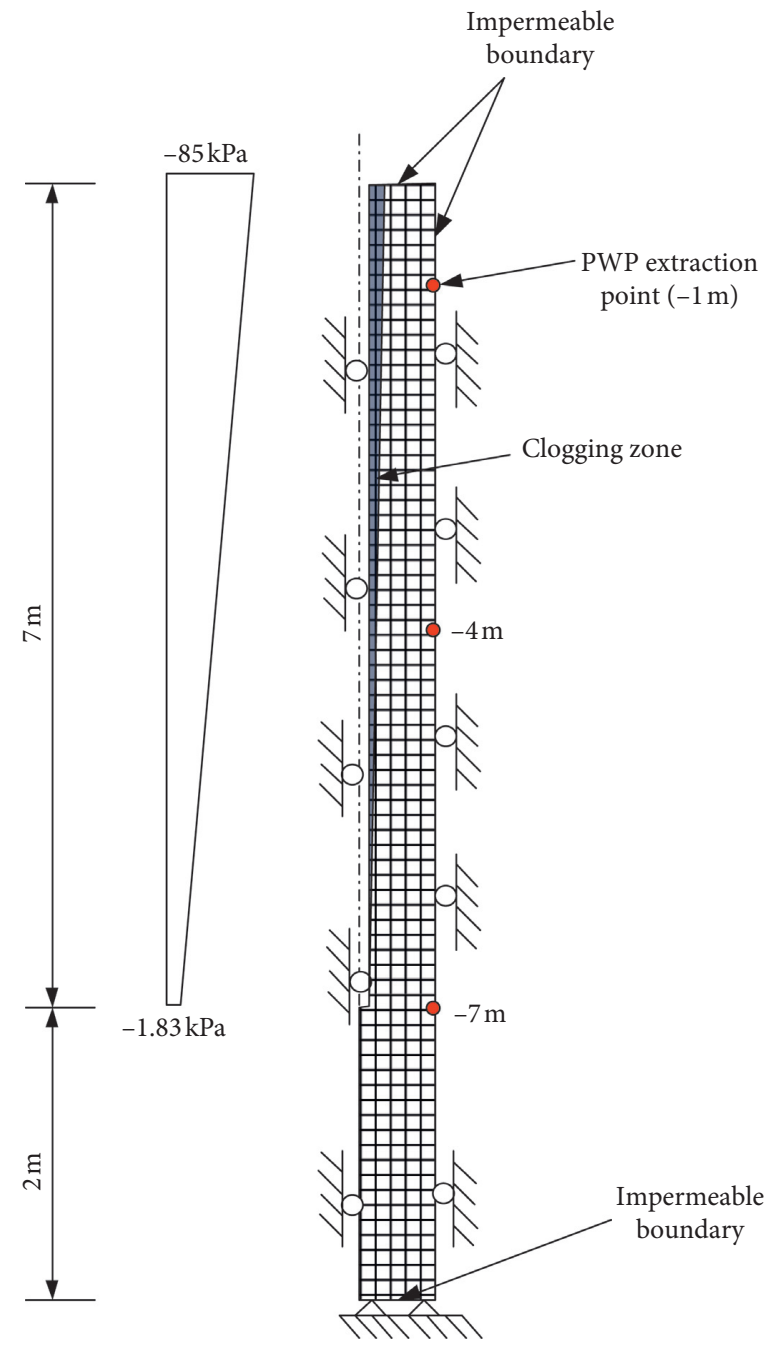

FIGURE 12: Finite-element mesh.

TABLE 5: Material properties.

\begin{tabular}{lccc}
\hline Layer & $C_{k}$ & $\log$ bulk modulus $M$ & $k_{\mathrm{c} 0}$ (within clogging zone) \\
\hline Dredged slurry \#1 & 0.48 & 0.76 & $1.6 \times 10^{-11} \mathrm{~m} / \mathrm{s}$ \\
Dredged slurry \#2 & 0.69 & 1.24 & $2 \times 10^{-11} \mathrm{~m} / \mathrm{s}$ \\
Muddy slurry & 0.76 & 0.75 & - \\
\hline
\end{tabular}

the first 45 days. Thereafter, the settlement of T3 began to slow down, whereas the settlement curves of $\mathrm{T} 1$ and $\mathrm{T} 2$ run closely to each other. It is seen that the surface settlement T3 is the smallest, which is $601.29 \mathrm{~mm}$ after 360 days of vacuum preloading; the surface settlement of T2 is close to those of $\mathrm{T} 1$, which are $701.82 \mathrm{~mm}$ and $730.97 \mathrm{~mm}$, respectively. It is clear that, even if the treatment time is doubled, the settlement of the foundation associated with larger PVD spacing (i.e., $900 \mathrm{~mm}$ ) would be considerably smaller than those with smaller PVD spacings (i.e., $700 \mathrm{~mm}$ and $800 \mathrm{~mm}$ ).

The comparisons on PWP dissipation between the three test foundations are shown in Figure 15. It is noticed that the PWP dissipates quickly when the vacuum pressure is applied. However, with the increase of time, the rate of PWP dissipation is decreasing. As being observed in the field tests, the PWP dissipations generally decrease with the increasing 


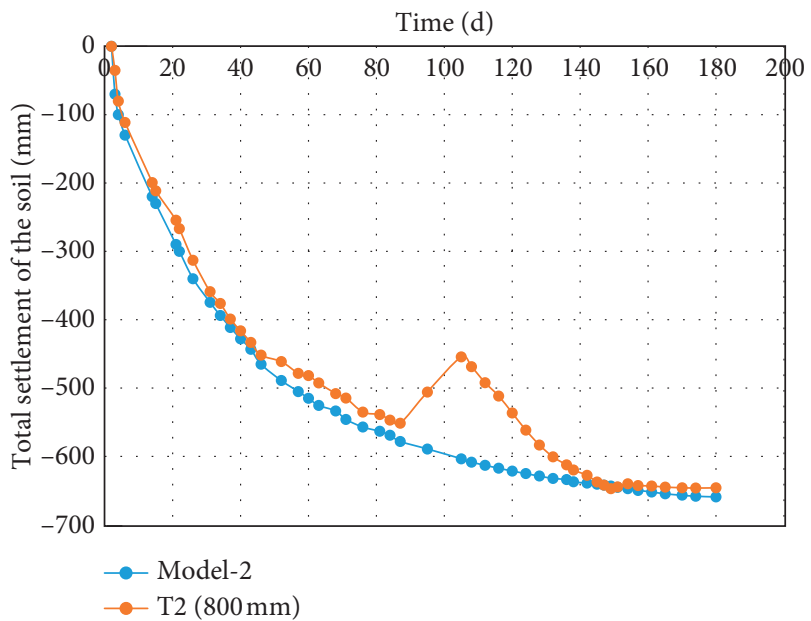

(a)

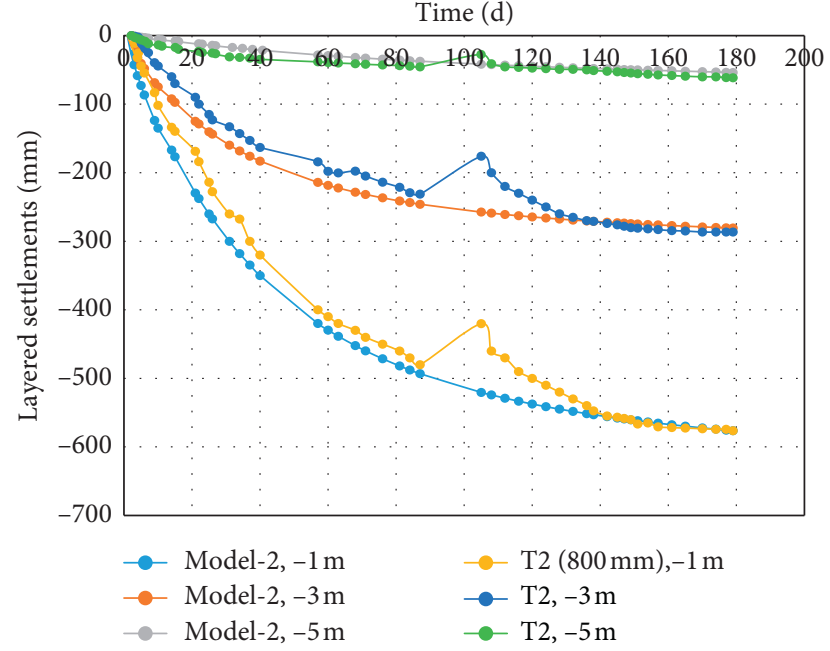

(b)

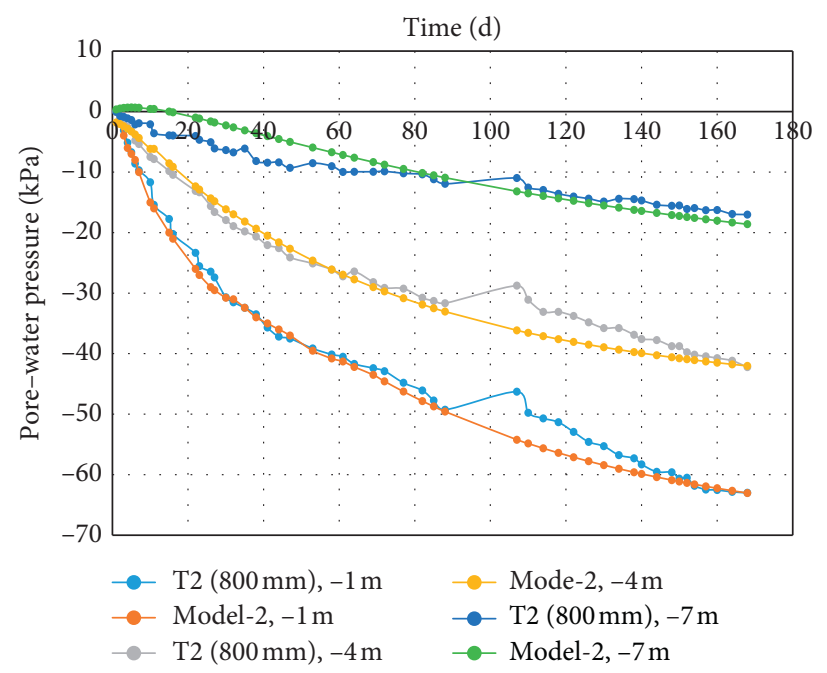

(c)

FIGURE 13: Comparison of numerical solution and measured data: (a) surface settlement; (b) layered settlements; (c) pore water pressures.

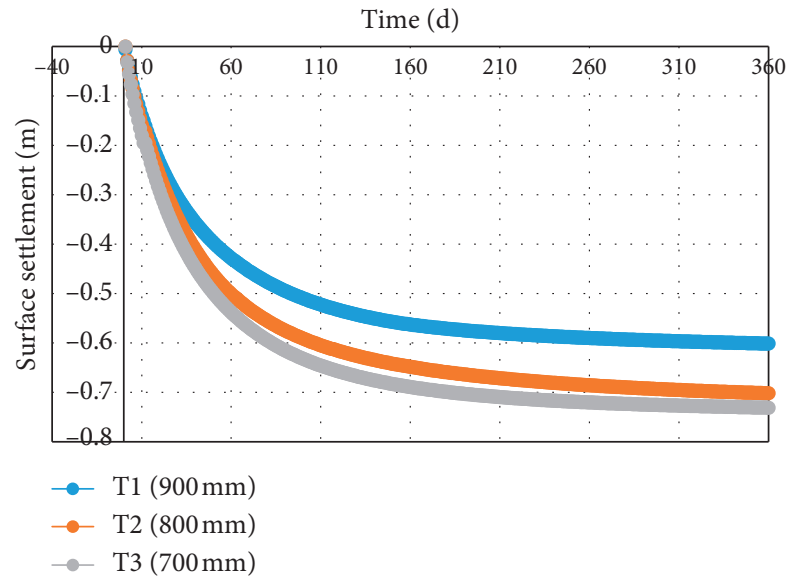

FIGURE 14: Surface settlement from different computational models. 


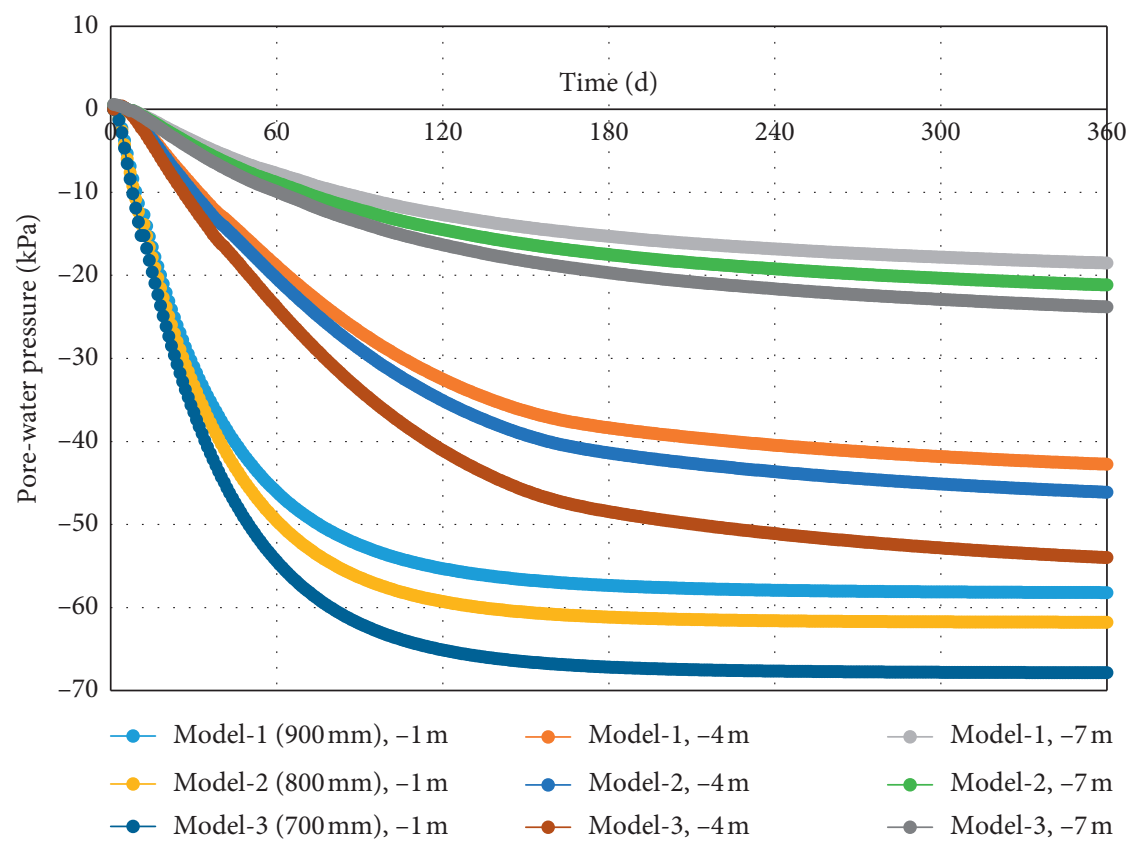

Figure 15: Pore pressure from different computational models.

of the burying depth. Similarly, it is shown that the PWP dissipation of the foundation associated with a larger PVD spacing (i.e., $900 \mathrm{~mm}$ ) would be less than those with smaller PVD spacings (i.e., $700 \mathrm{~mm}$ and $800 \mathrm{~mm}$ ), even though the treatment time has been doubled.

\section{Conclusions}

In this article, field test was conducted on vacuum treatment effects of a dredged slurry ground considering three PVD spacings. Comparisons have been made on the settlement and the pore water pressure dissipation to signify the influences of PVD spacing on the treatment effects. According to the three PVD spacings in the field test, three finite element models have been established to reproduce the vacuum consolidation process of the dredged slurry. After incorporating the vacuum pressure attenuation effects and the geometrical/hydraulic properties of the clogging zone into the numerical model, the simulated results including the surface settlement, the layered settlement, and the pore water pressure dissipations generally agree with the test results. Through analysis on the test and simulated results, the following conclusions can be drawn:

(1) Except from the consolidation rate, the final stable values of settlements and pore water pressure dissipations of foundation associated with larger PVD spacing are smaller than those with smaller spacing.

(2) The above observation can be attributed to the impeded seepage and the increased vacuum pressure attenuation, which are the direct consequences of the clogging phenomenon inherent to PVD treatment of dredged slurry by vacuum.

(3) According to the principle of effective stress, less pore water pressure dissipation during the vacuum consolidation means smaller gain in the soil strength. Accordingly, from our study on vacuum treatment of slurry ground, it is suggested that the PVD spacing should be determined by due considerations on the desired consolidation rate, and more importantly, on the absolute value of the pore water pressure that needs to be dissipated.

\section{Data Availability}

The raw/processed data required to reproduce these findings cannot be shared at this time as the data also form part of an ongoing study.

\section{Conflicts of Interest}

The authors declare that they have no conflicts of interest.

\section{Acknowledgments}

This work was financially supported by grants from the National Natural Science Foundation of China (grant no. 51879234) and from the enterprise (grant no. KY2018-HY$10)$.

\section{References}

[1] Y. Cai, Z. Xie, J. Wang, P. Wang, and X. Geng, "New approach of vacuum preloading with booster prefabricated vertical drains (PVDs) to improve deep marine clay strata," Canadian Geotechnical Journal, vol. 55, no. 10, pp. 1359-1371, 2018.

[2] J. Wang, J. Ni, Y. Cai, H. Fu, and P. Wang, "Combination of vacuum preloading and lime treatment for improvement of dredged fill," Engineering Geology, vol. 227, pp. 149-158, 2017.

[3] J. Wang, Z. Fang, Y. Cai, J. Chai, P. Wang, and X. Geng, "Preloading using fill surcharge and prefabricated vertical 
drains for an airport," Geotextiles and Geomembranes, vol. 46, no. 5, pp. 575-585, 2018.

[4] H. Y. Lei, Y. Hu, G. Zheng, J. J. Liu, L. Wang, and Y. N. Liu, "Improved air-booster vacuum preloading method for newly dredged fills: laboratory model study," Marine Georesources Geotechnolgy, vol. 38, no. 5, 2019.

[5] Y. Cai, H. Qiao, J. Wang, X. Geng, P. Wang, and Y. Cai, "Experimental tests on effect of deformed prefabricated vertical drains in dredged soil on consolidation via vacuum preloading," Engineering Geology, vol. 222, pp. 10-19, 2017.

[6] N. He, Y. Cui, L. Liu, X. Chen, Q. Feng, and Y. Deng, "Colloid effect on clogging mechanism of hydraulic reclamation mud improved by vacuum preloading," Canadian Geotechnical Journal, vol. 56, no. 5, pp. 611-620, 2019.

[7] L. Shi, Q. Q. Wang, S. L. Xu, X. D. Pan, H. L. Sun, and Y. Q. Cai, "Numerical study on clogging of prefabricated vertical drain in slurry under vacuum loading," Granular Matter, vol. 20, no. 4, 2018.

[8] Y. Cai, Y. Zhou, P. Wang, L. Shi, and J. Wang, "Calculation on settlement of dredged slurry treated by vacuum preloading method with consideration," Rock and Soil Mechanics, vol. 11, pp. 1-10, 2020.

[9] J. Wang, Y. Q. Cai, J. J. Ma, and J. Chu, "Improved vacuum preloading method for consolidation of dredged clay-slurry," Geotechnical and Geoenvironmental Engineering, vol. 142, no. 11, 2016.

[10] G. Mesri and A. Q. Khan, "Ground improvement using vacuum loading together with vertical drains," Journal of Geotechnical and Geoenvironmental Engineering, vol. 138, no. 6, pp. 680-689, 2012.

[11] R. D. Holtz, "Preloading with prefabricated vertical strip drains," Geotextiles and Geomembranes, vol. 6, no. 1, pp. 109-131, 1987.

[12] P. Wang, F. Yu, Y. Zhou, and J. Wang, "Effect of a sealed connector on the improvement of dredged slurry under vacuum preloading," Proceedings of the Institution of Civil Engineers-Geotechnical Engineering, vol. 173, no. 3, pp. 254261, 2020.

[13] W. H. Zhou, T. M. H. Lok, L. S. Zhao, G. X. Me, and X. B. Li, "Analytical solutions to the axisymmetric consolidation of a multi-layer soil system under surcharge combined with vacuum preloading," Geotextiles and Geomembranes, vol. 45, no. 5, pp. 487-498, 2017.

[14] D. Basu and M. Prezzi, "Effect of the smear and transition zones around prefabricated vertical drains installed in a triangular pattern on the rate of soil consolidation," International Journal of Geomechanics, vol. 7, no. 1, pp. 34-43, 2007.

[15] D. Basu and M. Prezzi, "Design of prefabricated vertical drains considering soil disturbance," Geosynthetics International, vol. 16, no. 3, pp. 147-157, 2009.

[16] S. Hansbo, "Consolidation of fine-grained soils by prefabricate drains," Proceedings of the International Conference on Soil Mechanics and Foundation Engineering, vol. 3, pp. 677$682,1981$.

[17] J. C. Chai, S. Hayashi, and J. P. Carter, "Characteristics of vacuum consolidation," in Proceedings of the International Conference on Soil Mechanics \& Geotechnical Engineering, Osaka, Japan, January 2005.

[18] V. Choa, "Drains and vacuum preloading pilot test," in Proceedings of the 12th International Conference on Soil Mechanics and Foundation Engineering, Rio de Janeiro, pp. 1347-1350, Rotterdam, Netherlands, August 1989.
[19] J. Chu, S. W. Yan, and H. Yang, "Soil improvement by the vacuum preloading method for an oil storage station," Géotechnique, vol. 50, no. 6, pp. 625-632, 2000.

[20] B. Indraratna, C. Bamunawita, and H. Khabbaz, "Numerical modeling of vacuum preloading and field applications," Canadian Geotechnical Journal, vol. 41, no. 6, pp. 1098-1110, 2004.

[21] J. Q. Shang, M. Tang, and Z. Miao, "Vacuum preloading consolidation of reclaimed land: a case study," Canadian Geotechnical Journal, vol. 35, no. 5, pp. 740-749, 1998.

[22] H. H. Mo, Q. C. Qiu, and Z. L. Dong, "Vacuum pressure distribution and pore pressure variation in ground improved by vacuum preloading," Canadian Geotechnical Journal, vol. 44, no. 12, pp. 1433-1445, 2007.

[23] G. Zhang, H. Mo, Z. Dong, and J. Zhao, "Analysis of relationship between vacuity and pore-water pressure in vacuum preloading," Rock and Soil Mechanics, vol. 26, no. 12, pp. 1949-1952, 2005.

[24] J. C. Chai, J. P. Carter, and S. Hayashi, "Vacuum consolidation and its combination with embankment loading," Canadian Geotechnical Journal, vol. 43, no. 10, pp. 985-996, 2006.

[25] B. Indraratna, C. Rujikiatkamjorn, and I. Sathananthan, "Analytical and numerical solutions for a single vertical drain including the effects of vacuum preloading," Canadian Geotechnical Journal, vol. 42, no. 4, pp. 994-1014, 2005.

[26] B. Indraratna, R. Zhong, and C. Rujikiatkamjorn, "An analytical model of PVD-assisted soft ground consolidation," Procedia Engineering, vol. 143, pp. 1376-1383, 2016.

[27] H. Wu and L. Hu, "Analytical and numerical solutions for vacuum preloading considering a radius related strain distribution," Mechanics Research Communications, vol. 44, pp. 9-14, 2012.

[28] Y. Zhou, P. Wang, L. Shi, Y. Cai, and J. Wang, "Analytical solution on vacuum consolidation of dredged slurry considering clogging effects," Geotextiles and geomembranes, vol. 49, no. 3, pp. 842-851, 2021.

[29] J. Shang, "Vacuum and surcharge combined one-dimensional consolidation of clay soils," Canadian Geotechnical Journal, vol. 39, no. 5, pp. 1126-1138, 2002.

[30] S. Leroueil, D. Perera, C. Rujikiatkamjorn, B. Indraratna, and R. Kelly, "Analytical model for vacuum consolidation incorporating soil disturbance caused by mandrel-driven drains," Canadian Geotechnical Journal, vol. 54, no. 4, pp. 547-560, 2017.

[31] S. J. Liu, X. Y. Geng, H. L. Sun, Y. Q. Cai, X. D. Pan, and L. Shi, "Nonlinear consolidation of vertical drains with coupled radial-vertical flow considering time and depth dependent vacuum pressure," International Journal for Numerical and Analytical Methods in Geomechanics, vol. 43, no. 4, pp. 767-780, 2019.

[32] F. Tavenas, P. Jean, P. Leblond, and S. Leroueil, "The permeability of natural soft clays. Part II: permeability characteristics," Canadian Geotechnical Journal, vol. 20, no. 4, pp. 645-660, 1983.

[33] Dassault Systèmes, ABAQUS Version 2017 [Computer Software], Dassault Systèmes, Providence, RI, USA, 2017. 